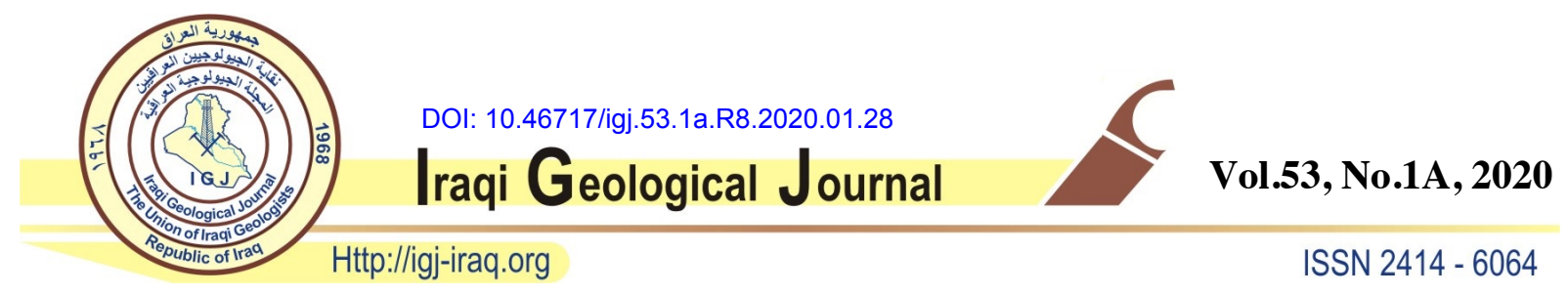

\title{
SYNCHROTRON BASED MICRO-MAPPING AND XAFS INVESTIGATION OF Fe-Mn AND EPIGENETIC INTERGROWTH WITHIN THE CAMBRIAN SHALLOW MANGANESE DEPOSITS, SOUTH JORDAN
}

\author{
${ }^{1}$ Tayel El-Hasan ${ }^{*}{ }^{2}$ Messaoud Harfouche, ${ }^{3}$ Allayth Aldrabee, and ${ }^{4}$ Diane Eichert \\ ${ }^{1}$ Department of Chemistry, Mutah University, Mutah, Jordan \\ ${ }^{2}$ SESAME synchrotron, Allan, Al-Balq'a \\ ${ }^{3}$ Jordan Atomic Energy Commission, Shafa Badran, Amman, Jordan \\ ${ }^{4}$ Elettra-Sincrotrone Trieste, Italy \\ *Email: tayel@mutah.edu.jo
}

Received: 10 April 2019; accepted: 6 September 2019

\begin{abstract}
The current work investigates the Cambrian Manganese ore deposits from Wadi Dana at central Wadi Araba region. This investigation aims to unravel the chemistry and microtextures of the mineral paragenetic sequence for these manganese ore deposits. Particularly the Fe-Mn intimate intergrowth micro texture and the epigenetic Mn mineralization associated with $\mathrm{Cu}$ minerals. The combination of the synchrotron-based $X$-ray fluorescence (syn-XRF) micro-mapping and X-ray absorption fine structure (XAFS) techniques were used. They provide a clear picture of the elemental distribution of $\mathrm{Mn}, \mathrm{Fe}, \mathrm{Cu}$, and $\mathrm{Pb}$ and other elements presented within the ore micro textures. Besides, it determines the exact elemental speciation. The results obtained gave a better understanding of the elemental atomic structures and eventually the depositional environment. Particularly, the syn-XRF micro-mapping reveals the existing of many successive evolution stages in the Mn ores. Besides, the X-ray Absorption Near Edge Structure (XANES) results showed that the micro-rhythmic texture is changing from $\mathrm{Mn}^{+4}$ (Pyrolusite) into $\mathrm{Fe}^{+3}$ (Hematite). This is evidence for the role of Eh as the main controlling factor during the ore formation. Eventually, indicating tentatively the paleoceanography setting of the Mn deposits. This is related to the continuous transgression-regression on the sea level in a semi-closed sea. Keywords: Cambrian; Shallow Manganese; Pyrolusite; Hematite; Synchrotron-Based X-Ray Fluorescence Micro-Mapping; Eh-pH
\end{abstract}




\section{INTRODUCTION}

The main manganese deposit outcrops at Wadi Dana area, at the central Wadi Araba region 9 (Fig. 1). Manganese is hosted in the middle Cambrian Dolomite Limestone Shale Unit (DLSU). This formation consists of the lower calcareous part and upper siliceous part. The manganese ores are found as disseminations, thin intercalations, lenses, concretions, and bands (El-Hasan et al. 2001a). Since the manganese of Wadi Dana area is the larger manganese deposit in Jordan, it was studied by many authors (Khoury, 1986; Shaltoni, 1988; El-Hasan, 1999; El-Hasan and Lataifeh, 2001; El-Hasan et al., 2000, 2001b \& 2008). Wadi Dabbah ore body is composed of massive bands of 2-3 m thickness with a limited lateral spread. The mineral constituent is very complicated and shows intimate growth of Cryptomelane, Hollandite, Psilomelane, Pyrolusite, and Hematite. Additionally, a significant concentration of $\mathrm{Cu}, \mathrm{K}$, and $\mathrm{Ba}$ were detected, as well as traces of $\mathrm{Zn}, \mathrm{Ni}$ and Co. Hematite is the main gangue mineral. It is a common mineral in supergene Mn deposits, (Ghosh, and Dean, 1980). In previous studies, hematite was identified by ore microscopy and XRD, to be associated with Pyrolusite.

High $\mathrm{Mn}$ ore deposits typically present intergrowth of $\mathrm{Fe}$ and $\mathrm{Mn}$, ranging from $\mathrm{Fe}$ Oxide (i.e. Hematite) to Mn-Oxide (i.e. Pyrolusite) in a fish-scale or wave-like texture (Fig. 2). This is a unique phenomenon which might be attributed to various reasons and complex processes during ore formation, which is mainly related to the Eh-pH conditions. This hypothesis was not examined in depth by using conventional SEM and EPMA techniques (ElHasan et al., 2001b).

The synchrotron applications, particularly XRF and XAFS techniques are ideal for mineral chemistry studies because bulk XAFS shows limitation to determine the Mn species in heterogeneous systems. It probes a volume of several square millimeters, thereby averaging over all the atoms of a certain atomic number in the system under study, regardless of their chemical state. However, when Mn is present in multiple phases, the atomic shells from the different species overlap and cannot be distinguished when there is a mixture. However, using a coarse spatial resolution beam $\left(\sim 220 \times 110 \mu \mathrm{m}^{2}\right)$ to perform coarse elemental fluorescence mapping on the sample will help to identify the different phases and thus select target zones of interest achieve XAFS data measurements. By using a relatively focused beam it is possible to access the small domain, which allows to track spatial changes in the composition and to differentiate the multiple phases. Thus, a combination of XRF and XAS using small beam is an ideal tool for the analysis of extremely heterogeneous materials in general and will give us a clear image and indications about the determining factor in developing the intimate $\mathrm{Mn}$ growth, through tracing the oxidation valences changes for both $\mathrm{Fe}$ and $\mathrm{Mn}$ ions. 
Therefore, synchrotron based X-ray Absorption Fine Structure (XAFS) (i.e. XANES) is a technique that can provide detailed chemical and structural information about a specific element with minor or no pre-treatments (Hunter and Bertsch, 1998). X-ray Absorption Spectroscopy (XAS) has become the method of choice for probing the local structure at the short and medium range order in particular when the structure is disordered. The XANES has been successfully used for the discrimination of different oxidation states in chromium in treated wood (Strub, 2008), in addition to glass samples (Görner, 2006). Many previous workers have used the synchrotron radiation in mineralogical and geochemical applications, such as Buehn et al. (1999), they had determined the elemental composition of Burbankite was determined by a combination of SEM-EDX on opened inclusions and synchrotron-XRF analysis on unopened wafers. Moreover, Synchrotron radiation-induced X-ray fluorescence (SR-XRF) analysis was used to study the chemical composition of precious renaissance silverpoint drawings (Reiche et al., 2004). Its use has demonstrated the variable reactivity and speciation of elements in different structural systems. XANES spectroscopy has shown to be extremely useful for a quantitative, fast and reliable determination of the oxidation state in the soils (Peterson et al., 1997). The XANES techniques were used successfully in determining the $\mathrm{Cr}$ (VI)/Cr (III) within oil shale ash (El-Hasan et al. 2011). Recently, EXAFS techniques were used for determining the Cr-host mineral matrix in the solidified oil shale ashes (ElHasan et al., 2019). Pre-edge features in the XANES area due to a bound-state transition contain information about the geometry of the photo-absorber, for instance, in the case of Mn and Fe will represent a clear fingerprint of the redox of this environmentally related element. Therefore, the use of powerful synchrotron-based XRF and XAFS techniques will allow us to estimate the elemental speciation of Mn-ore mineral, to determine the redox state of the Mn and $\mathrm{Fe}$ and to explore, at the atomic level, the local structure behavior around these two elements. Moreover, the high level of monochromaticity and tunability of the X-ray beam is required to probe the chemical speciation and the local arrangements of the atoms of the selected elements. Previously; El-Hasan (1999) has identified fish-scale texture using SEM. It is a prerequisite to our experiment and it is a feature offered only by synchrotron facilities. However; it qualitatively identified the total $\mathrm{Fe}$ and total $\mathrm{Mn}$ without identifying their valances, which cause the use of the Eh-pH diagram uncertain. Therefore, the main incrimination in this current work is providing us with exact $\mathrm{Fe}$ and $\mathrm{Mn}$ speciation that sharply pinpoints for the exact Eh-pH conditions during ore formation and the events that cause the formation of this texture. Therefore, this study aimed to execute several XRF mapping and XANES measurements for high and low grade Mn-ores from Wadi Dana deposits, to clarify the paleo-oceanographic and paleo-environmental setting dominating 
during the ore formation. Moreover, to confirm the mineralogical paragenetic sequence and ore evolution stages.

\section{METHODOLOGY AND MATERIALS}

The samples of this study were brought from the high-grade ore outcropping at Wadi Dabbah (Db) which have an average ore grade 26.1 (Vol. \% of Mn) and low-grade ore outcropping at Wadi Khaked (Kh) (Fig. 1). The Mn ore samples were polished thin section impregnated into resin base and with very smooth polished faces by very fine silicon carbide spray. The area of ore polish faces is about $1.5 \times 2 \mathrm{~cm}$ in diameter, while the total resin sections are from $2-2.5$ $\mathrm{cm}$ in diameter. The use of conventional methods such as XRF and XRD was neither able to give a clear answer about the micro texture of $\mathrm{Mn}, \mathrm{Fe}$ and $\mathrm{Cu}$ minerals nor their oxidation state (El-Hasan, 1999).

An experiment was carried out at the X-Ray Fluorescence beamline at Elettra. XRF and XAFS data were collected at the K-edges of Mn (6.539 keV), Fe (7.112 keV) and $\mathrm{Cu}(8970$ $\mathrm{keV}$ ) (Jerk et al., 2014). The selected high-grade Mn ores samples were used to improve the quality of mapping and XAFS measurements. Reference samples were used for the redox comparison such as compounds with $\mathrm{Mn}(\mathrm{II}), \mathrm{Mn}(\mathrm{III}), \mathrm{Mn}(\mathrm{IV}), \mathrm{Fe}(\mathrm{II}), \mathrm{Fe}(\mathrm{III})$ or Fe (IV) species. The analysis was accomplished with 15 shifts used to collect high quality XAFS data up to $\mathrm{k}=\sim 13 \AA$ - 1 . Assuming a minimum of 3 scans per sample for statistics, we end up with 6 hours per sample.

The beam settings are as follows: for the mapping: - step size of 200 microns horizontally, and 80 microns vertically. The excitation energy of $10500 \mathrm{eV}$. The EDXRF detector at 10 to $20 \mathrm{~mm}$ from the sample (depending on the sample), and with a shaping time $<90 \mathrm{kcps}$. As for the XANES: step size of $0.5 \mathrm{EV}$ (i.e. 501 points in each spectrum), the integration time of $3 \mathrm{~s} /$ point usually the spectra were repeated at least twice to ensure a good $\mathrm{S} / \mathrm{N}$ ratio. The EDXRF detector at 10 to $30 \mathrm{~mm}$ from the sample plane, with a shaping time < $130 \mathrm{kcps}$. The energy resolution is one intrinsic to the Si (111) pair of crystal, at the energy of excitation considered; with up to $1 \mathrm{eV}$ above for the $\mathrm{Mn}, \mathrm{Fe}$ and $\mathrm{Cu}$ edges for the investigated samples.

The selected samples underwent comprehensive and details elemental mapping at the first step. Then, based on the mapping hot spots were targeted by syn-XRF micro mapping and XANES measurements at K-edges of $\mathrm{Mn}, \mathrm{Fe}$ and $\mathrm{Cu}$. The samples were categorized according to ore bodies in terms of Mn ore grade as follows: 1- Low-grade ores (KH2) and 2High-grade ores (Db9 and Db13). 


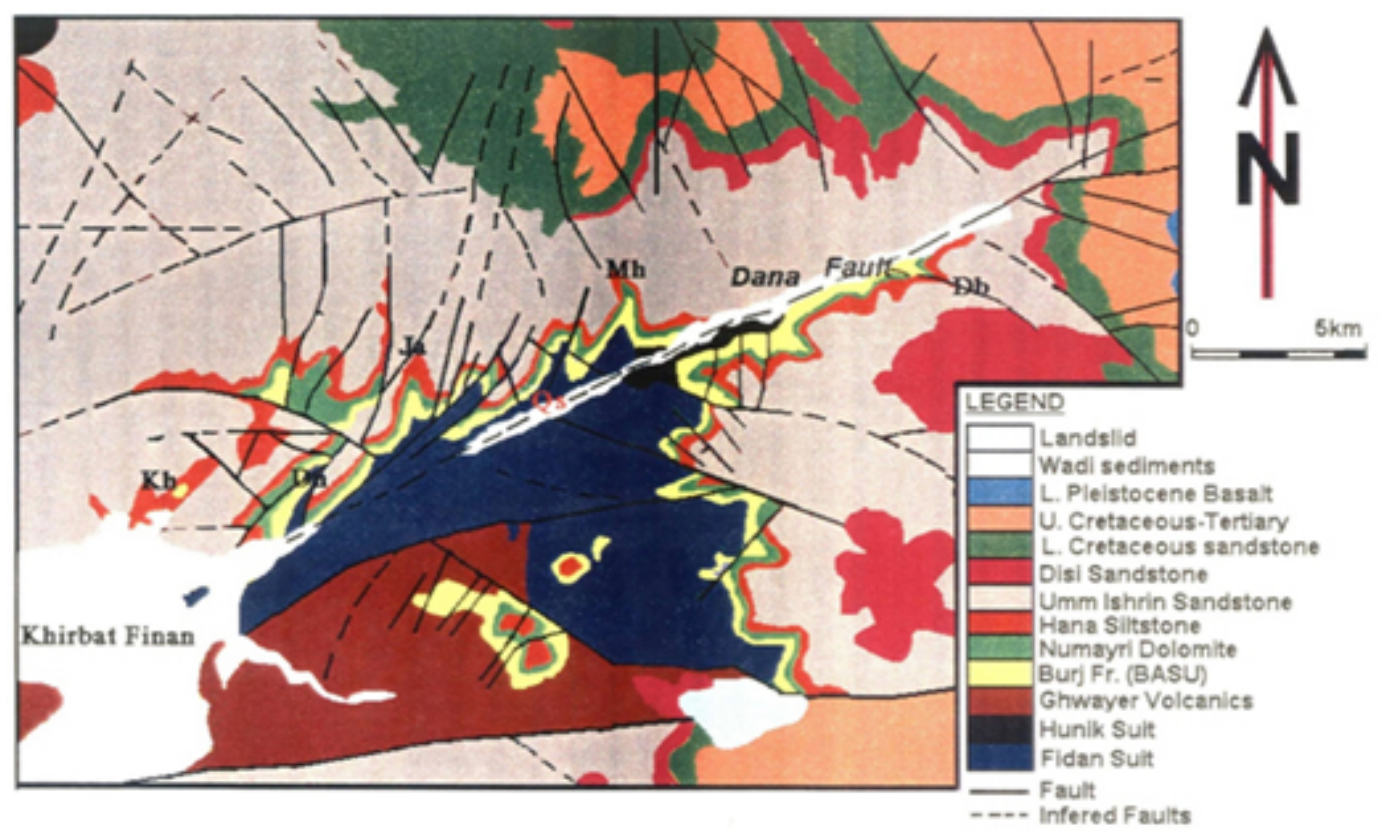

Fig. 1: Study area map and the location of studied samples (after El-Hasan, 1999)

\section{RESULTS}

\section{High-grade Mn Ores}

The previous SEM investigations of these samples had revealed the presence of fish-scales texture within the high grade Mn-ores at Wadi Dabbah (e.g. Db9 \& Db 13). The rhythmic nature of this wave-like texture that ranges from continues cycles from pure $\mathrm{Mn}$ to pure $\mathrm{Fe}$ ends. This structure and mineral changes need to be clarified by identifying the metal valences by executing the XANES measurements for several points taken in cross-section from Mn-end into Fe-end. The mapping results confirmed the cyclic nature of both $\mathrm{Fe}$ and $\mathrm{Mn}$. Moreover, the syn-XRF micro-mapping confirmed the presence of secondary $\mathrm{Pb}$-phase as epigenetic veinlets (Fig. 2).

After allocating the best cross-section, Syn-XRF elemental mapping, which helped in allocating the Mn and Fe XANES results reveals the changing from Mn (IV) (e.g. Pyrolusite $\mathrm{MnO}_{2}$ ) to $\mathrm{Fe}(\mathrm{III})$ (e.g. Hematite $\mathrm{Fe}_{2} \mathrm{O}_{3}$ ), as shown in Figure (3). The implication for this finding is essential for determining the paleo-oceanographic conditions in terms of dominating Eh-pH for the lower- middle Cambrian shallow marine manganese ores. 


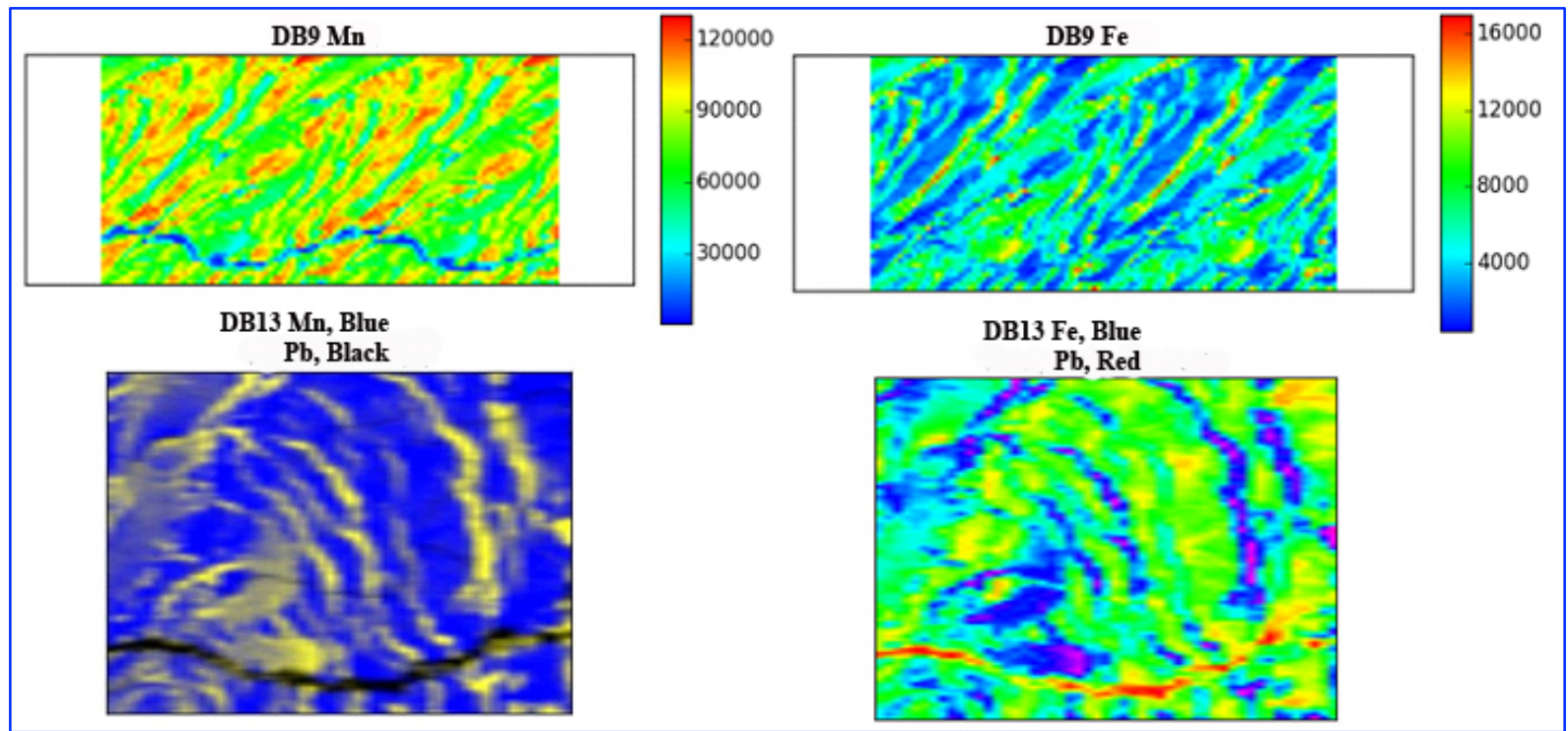

Fig. 2: Synchrotron XRF micro-mapping for Samples from high-grade Mn ores bodies (a) DB9 and (b) DB13; shows epigenetic Pb-Mn oxide veinlets
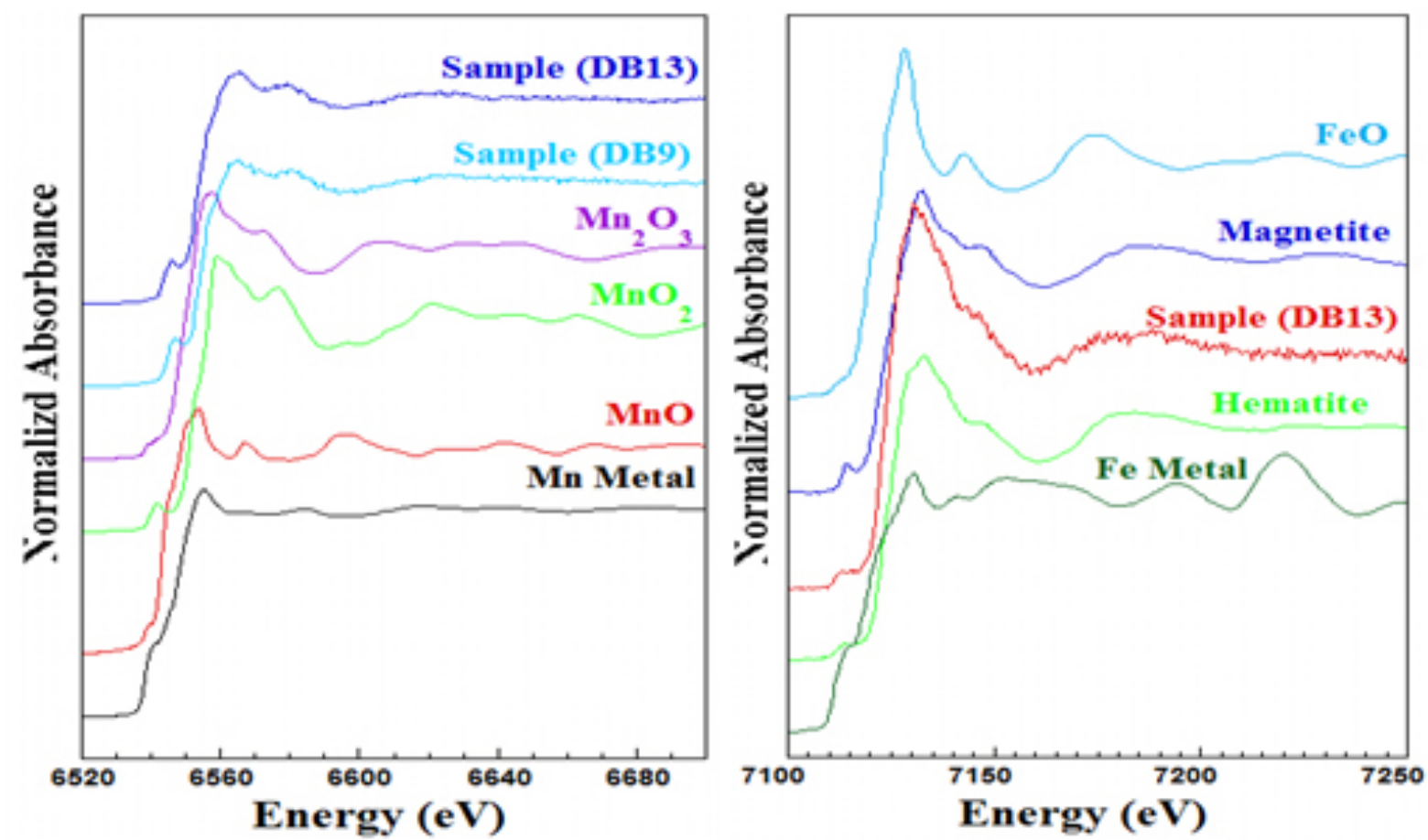

Fig. 3: XANES for Mn, Fe and Pb for samples from high-grade ores (Db9 and Db13)

\section{Low-grade Mn Ores}

The results of Syn-XRF micro mapping of the low-grade Mn ores from Wadi Khaled (e.g. $\mathrm{KH} 2$ ) representing the ideal epigenetic type of mineralization. The mapping included $\mathrm{Mn}, \mathrm{Fe}$, $\mathrm{Cu}$, and $\mathrm{Pb}$. The obtained results were very important in tracing the various syngenetic and epigenetic manganese ore mineralization (Fig. 4). To determine the mineral phases a selected hot spot was analyzed. The results of Syn-XRF micro-mapping reveal the presence of $\mathrm{Pb}-\mathrm{Mn}$ oxide (Coronadite) as epigenetic phase intruding the primary supergene $\mathrm{Cu}$ - Carbonate 
mineral (Chryscolla), Fe was also associated with $\mathrm{Mn}$, which is presented in the solid solution phase (Hollandite) (El-Hasan, 1999, El-Hasan and Al-Malabeh, 2009) (Fig. 5). Furthermore, the XANES measurements of the $\mathrm{Cu}$ and $\mathrm{Mn}$ show that they are found in higher oxidation states i.e. $\mathrm{Mn}$ (IV) and $\mathrm{Cu}(\mathrm{II})$ ) as showing in Figure (6). Such phases indicate highly oxidizing conditions that provide evidence for the epigenetic type of mineralization, which might be attributed to descending meteoric water effect.

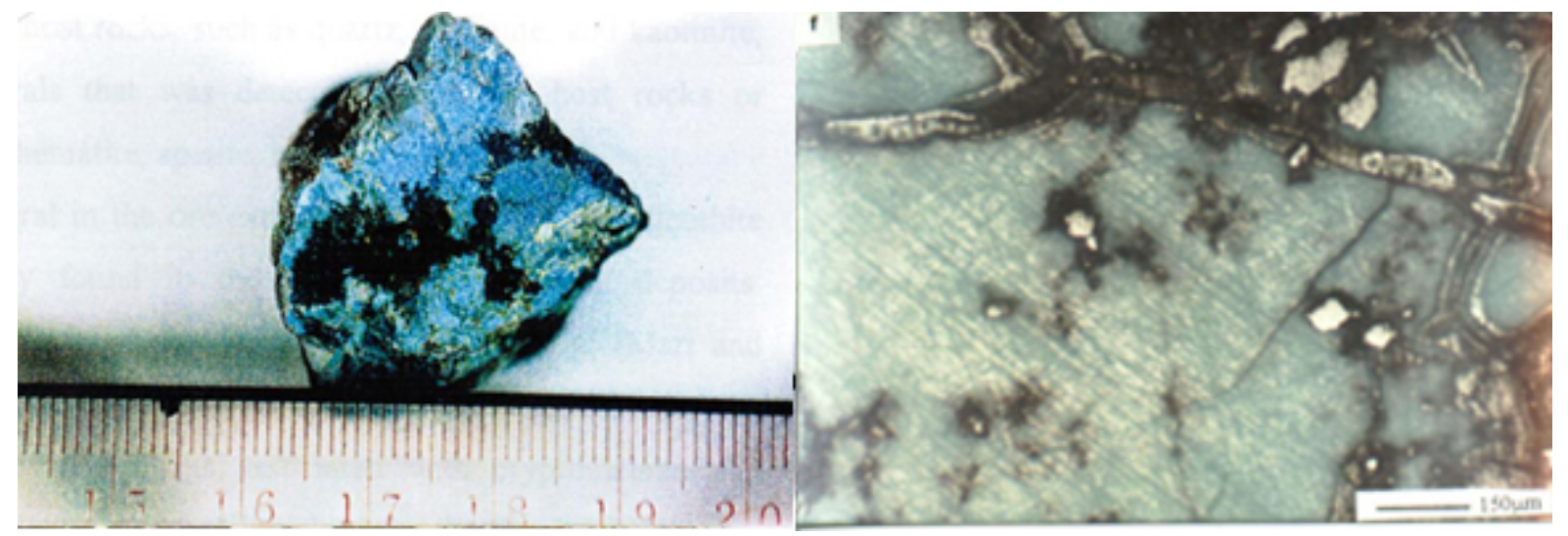

Fig. 4: KH2 hand specimen samples and reflecting microscope photo; showing the manganese epigenetic phase (Coronadite) introducing into the $\mathrm{Cu}$ - mineral (Chryscolla)

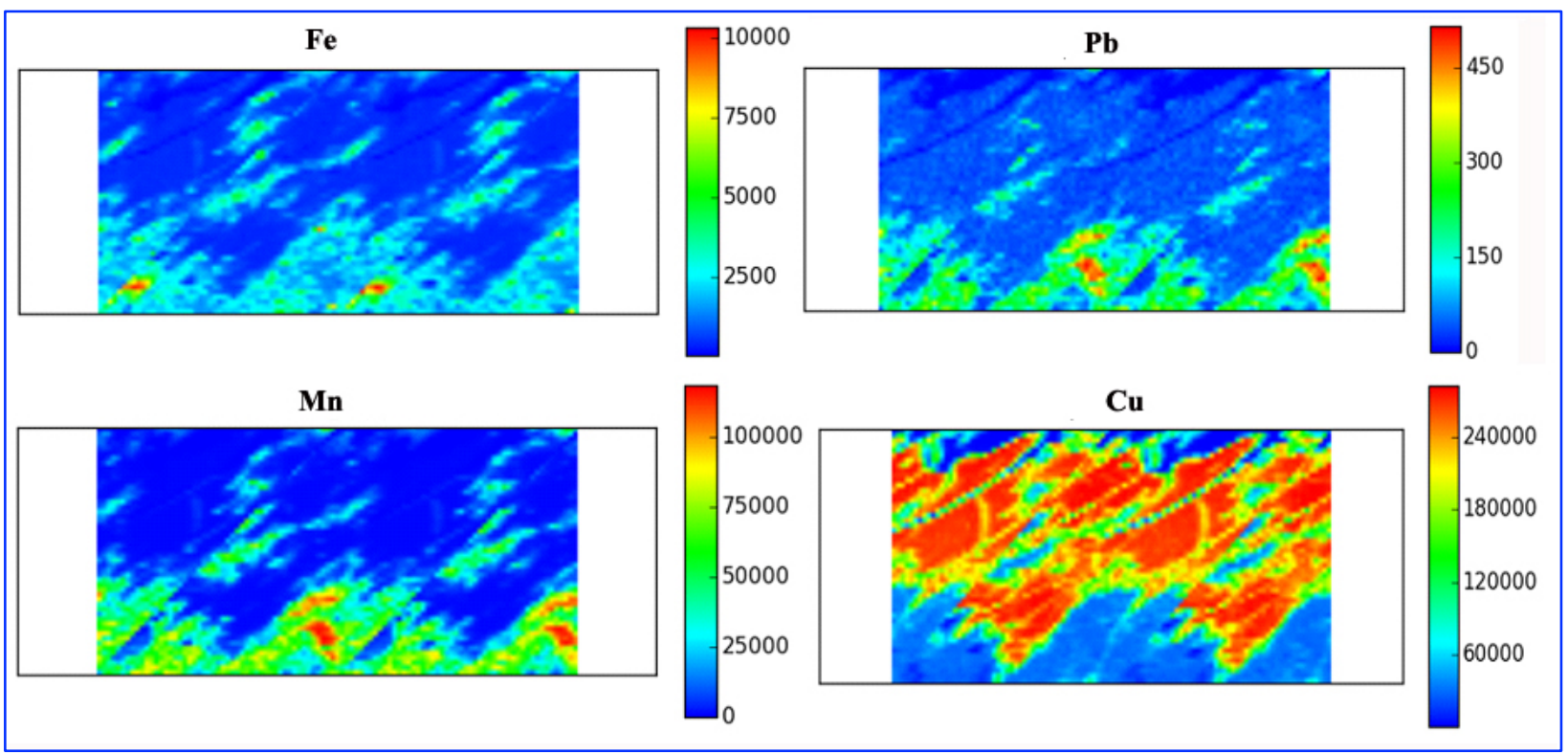

Fig. 5: Synchrotron micro-mapping of $\mathrm{Fe}, \mathrm{Mn}, \mathrm{Cu}$ and $\mathrm{Pb}$, showing epigenetic $\mathrm{Pb}-\mathrm{Mn}$ oxides (Coronadite) intruding the supergene $\mathrm{Cu}$-mineral (Chryscolla) 

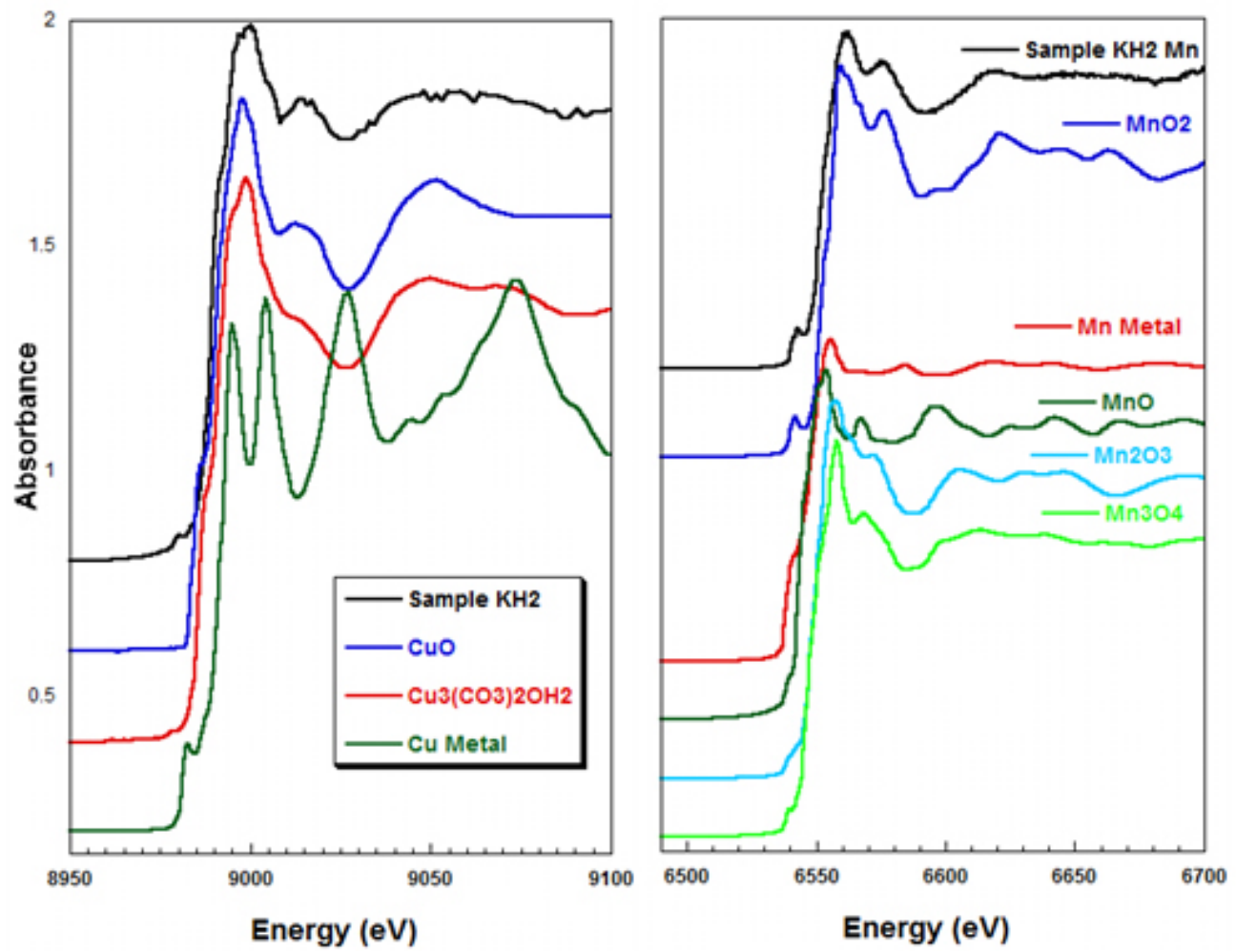

Fig. 6: The XANES data taken for sample KH2 confirms the presence of $\mathrm{Mn}^{+4}$ and $\mathrm{Cu}^{+2}$ species, indicating highly oxidizing environment

\section{DISCUSSION}

The intergrowth of $\mathrm{Fe}$ and $\mathrm{Mn}$ is considered a valuable tool for tracing the paleoenvironmental depositional conditions of $\mathrm{Mn}$ ore formation, as it identifying the paleooceanography settings. The results elucidate the exact Eh-pH conditions during formation, and thus lead to determine the precise phase diagram of the system Fe-Mn-O within the shallow marine environment. The high-grade Mn-ores are also rich in $\mathrm{Fe}$, forming a unique intergrowth between $\mathrm{Mn}$ and $\mathrm{Fe}$ oxides. This intergrowth was recognized by the changing from Fe-oxide into Mn-oxide in a fish-scale or wave-like texture (Fig. 2). The fish-scale and rhythmic nature of this intergrowth might be attributed to the continuous changing in sealevel status during Mn ore deposition (El-Hasan, 1999). This sea-level change will cause a continuous change in the Eh-pH conditions of the depositional environment; as mentioned in (Brookings, 1988). This hypothesis was roughly recognized using conventional SEM and EPMA methods (El-Hasan, 1999; and El-Hasan et al., 2001a). However, the Synchrotron XANES analysis provided precise identification of both existing Fe \& Mn oxidation states within this intergrowth. Through XANES measurements for Fe and Mn, this was carried out in form of spot or traverses within a complete fish scale texture cycle. XANES results confirm exactly that the controlling factor was the change in Eh rather than $\mathrm{pH}$. This might have attributed to the cyclic change in sea level during shallow sea-level more oxygen can reach 
the water that contain Mn ore and causing higher Eh values, causing Mn oxide to form. But during high sea-level periods thick water column prevents oxygen to penetrate to the ore causing lower Eh values, thus Fe oxide more preferably formed. As shown in Figure (7); higher Mn oxidation state mineral Mn(IV) (e.g. Pyrolusite) are start forming at Eh0.7 (V), whereas higher Fe oxidation such as Fe(III) (e.g. Hematite) starts at lower $\mathrm{Eh}=0.1$ (V), if we consider constant $\mathrm{pH}=7$ as normal seawater. Therefore, at shallow periods (i.e. low Sea-level) Pyrolusite $\left(\mathrm{MnO}_{2}\right)$ formed as a more oxidized environment is prevailing. Meanwhile, at thicker water periods (i.e. high sea-level) Hematite $\left(\mathrm{Fe}_{2} \mathrm{O}_{3}\right)$ would form in less oxidized environment.
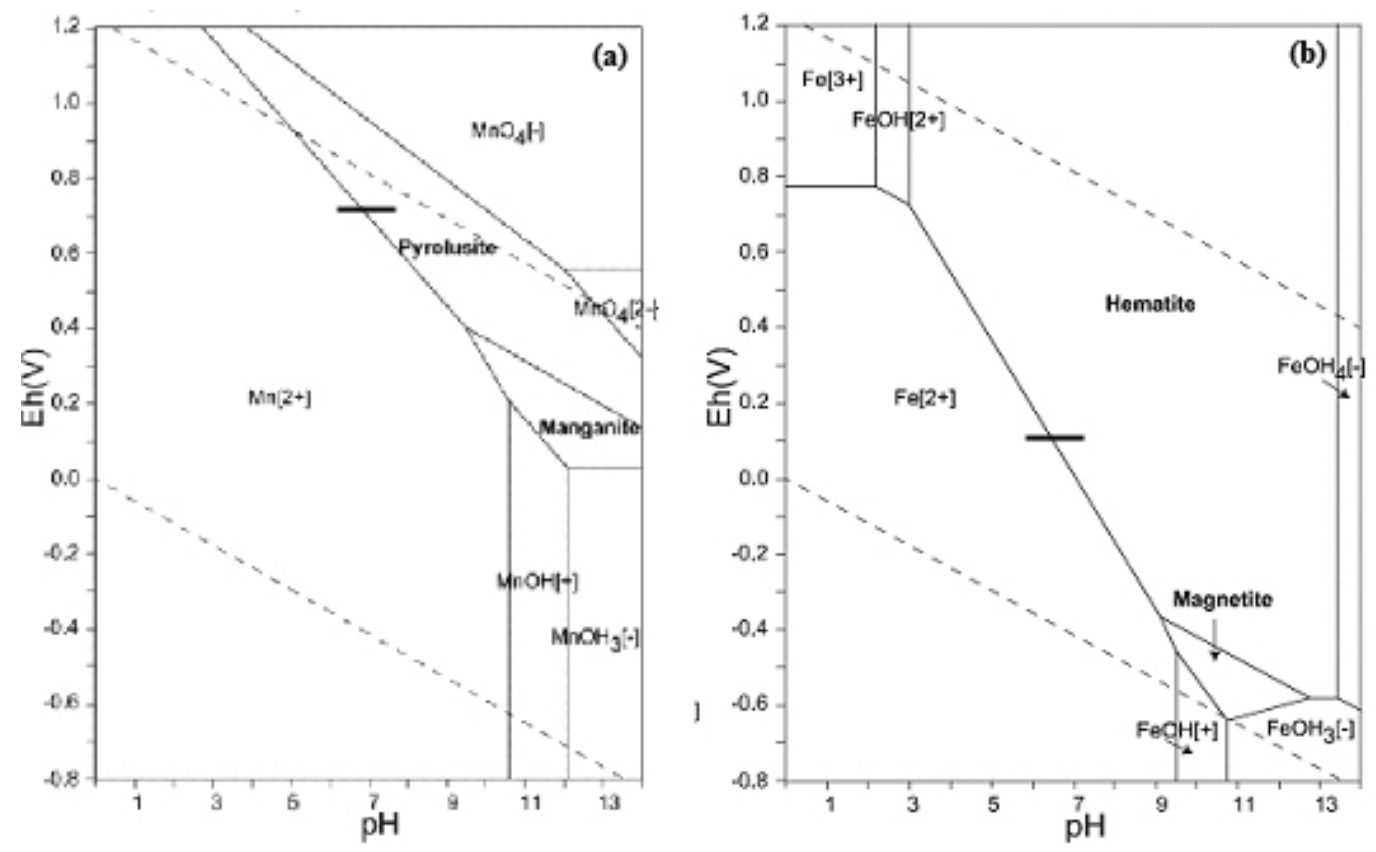

Fig. 7: Eh-pH stability diagrams for (a) Mn and (b) Fe species (Diagrams after Brooking, 1988; Force and Cannon, 1988)

The bulk mineral assemblage is typically of supergene manganese ore type. The microscopic and field observations indicate the presence of the three genetic stages. Primary ore stage, dominating the lower Cambrian, the ore was formed by sedimentary accumulation under a shallow marine environment. Followed in the middle Cambrian by the supergene enrichment stage, which was the dominant, and thus it is overprinting totally the primary ore features. Finally, the ore was affected by the epigenetic mineralization stage mainly affects the upper part of the main mineralized horizon (El-Hasan, 1999). Therefore, the projection on mineralization evolution stages indicates a semi closed seas environment. As well a continuous transgression -regression on the sea level. This can explain the changing in Eh 
values due to change in sea level. Similar depositional environment of shallow manganese deposits of Groote Eylandt (Australia) was proposed by Bolton and Frakes (1984).

\section{CONCLUSIONS}

Synchrotron XRF micro-mapping and XANES analyses were an ideal tool in providing detailed mineral micro-textures and precise identification of $\mathrm{Mn}, \mathrm{Fe}$ and $\mathrm{Cu}$ oxidation states. Moreover, from geochemical point of view, it is important to elucidate the exact prevailing Eh-pH conditions, eventually determining the paleo-oceanographic settings and ore depositional environment. The rhythmic wave - like micro texture changing from Hematite Fe (III) into Pyrolusite Mn(IV) is controlled mainly by Eh changing rather than $\mathrm{pH}$. The Eh was changing from $(0.7$ to $1.0 \mathrm{~V})$, caused by the change in sea level, indicating continuous transgression-regression of semi-closed sea environment. This would indicate the nature of the prevailing oceanography setting as semi closed seas. The Syn-XRF micro-mapping and XANES measurements provides a more logical explanation for the Mn ore evolution stages, and in particular the epigenetic $\mathrm{Pb}-\mathrm{Mn}$ oxide (Coronadite) intrusion into the primary $\mathrm{Cu}$ carbonate mineral (Chryscolla).

\section{ACKNOWLEDGMENT}

Beamtime was provided by Elettra-Sincrotrone Trieste under the framework of the proposal No. 20150153, and received financial support by ICTP. Therefore, the authors are grateful to ELETTRA and ICTP for their support.

\section{REFERENCES}

Bolton, B.R., and Frakes, L., 1984. On the origin of manganese giants: a preliminary comparative investigation of the Chistura (USSR) and Groote Eylandt (Australia) deposits. In: XXVII international Geological Congress. Moscow,VI(12): 46.

Brookings, D.G.,1988. Eh-pH diagrams for geochemistry. Springer-Verlag, Berlin, 176 pp.

Bühn, B., Rankin, A.H., Radtke, M., Martin Haller, M., and Knöchel, A., 1999. Burbankite, a (Sr,REE, Na, Ca)-carbonate in fluid inclusions from carbonatite-derived fluids: Identification and characterization using Laser Raman spectroscopy, SEM-EDX, and synchrotron micro-XRF analysis. American Mineralogist, 84(7-8):1117-1125.

El-Hasan, T., and Al-Malabeh, A., 2009. Mineralogy and chemistry of coronadite from Middle Cambrian manganese deposits at Wadi Dana, South Jordan. American Journal of Applied Sciences., 6(4): 576581.

El-Hasan, T., Al-Malabah, A., and Kumoro, K., 2008. Rare earth elements geochemistry of the Cambrian shallow marine manganese deposits at Wadi Dana, South Jordan. Jordan Journal of Earth and Environmental Sciences (JJEES)., 1(1):45-52.

El-Hasan, T., Al-Malabah, A., Kajiwara, Y., and Komuro, K., 2000. Petrology, mineralogy, and genesis of Wadi Dana Cambrian manganese deposit, Central Wadi Araba Region, Jordan. El-Sayed (Eds): Geology of the Arab world, Proceedings of the $5^{\text {th }}$ Int. Conf. on the Geology of the Arab world, Cairo Univ., 1: 391-404. 
El-Hasan, T., Al-Malabah, A., Kajiwara, Y., and Komuro, K. 2001a. Geochemical characteristics of the Cambrian manganese deposits of Central Wadi Araba, South Jordan. Iraqi J. Sci., Vol 42A (3): 1-39.

El-Hasan, T., and Lataifeh, M., 2001. Differentiation between various manganese deposits of Jordan using magnetization measurements. AL-Manarah, 7(1): 71-86.

El-Hasan, T., Kajiwara, Y., Komuro, K., and Al-Malabeh, A., 2001b. Petrology, mineralogy, and genesis of the Cambrian manganese deposit, central Wadi Araba region, Jordan. Qatar Univ. Science Journal. 21:101-117.

El-Hasan, T., Szczerba, W., Radtke, M., Riesemeier, H., Buzanich, G., and Kersten, M., 2011. Cr (VI)/Cr (III) and $\mathrm{As}(\mathrm{V}) / \mathrm{As}$ (III) Ratio Assessments in ordanian Spent Oil Shale Produced by Aerobic Combustion and Anaerobic Pyrolysis. Environmental Science \& Technology., 45(22): 9799-9805.

El-Hasan, T.M., 1999. Geology, Mineralogy, and Geochemistry of the Cambrian Manganese Deposits of Central Wadi Araba Region, Jordan. Tsukuba Univ. Ph.D. Thesis, 133pp.

El-Hasan, T.M., Nizar, A.J., and Nafeth, A., 2019. Hazardous toxic elements mobility in burned oil shale ash, and attempts to attain short- and long- term solidification. oil shale., 36(2S):226-249.

Force, E.R., and Cannon, W.F., 1988. Depositional model for shallow manganese deposits around black shale basins. Econ. Geol., 83: 93-117.

Ghosh, S.K., and Dean, W.E., 1980. Geochemistry of freshwater ferromanganese deposits in North America. In: Varentsov, I. and Grasselly, Gy. (eds): Geology and Geochemistry of Manganese. 3. Hungarian Academy of Science, Budapest, 255- 277.

Görner, W., Eichelbaum, M., Matschat, R., Rademann, K., Radtke, M., Reinholz, U., and Riesemeier, H., 2006. Non-destructive investigation of composition, chemical properties and structure of materials by synchrotron radiation., 48(9):540-544.

Hunter, D.B., and Bertsch, P.M., 1998. In situ examination of uranium contaminated soil particles by micro X-ray absorption and micro-flourescence spectroscopies, Journal of Radioanalyical and Nuclear Chemistry. 234:237-242.

Jark, W., Eichert, D., Luehl, L., and Gambitta, A., 2014. Optimization of a compact optical system for the beamtransport at the X-ray fluorescence beamline at Elettra for experiments with small spots. Advances in X-Ray/EUV Optics and Components IX. doi:10.1117/12.2063009

Khoury, H.N., 1986. On the origin of stratabound copper-manganese deposits in Wadi Araba, Jordan. Dirasat. Amman. 13: 227-247.

Peterson, M.L., Brown, G.E., Parkes, G.A., and Stien, C.L., 1997. Differential redox and sorption of CrIII/VI on natural silicates and oxide minerals: EXAFS and XANES results. Geochem. Cosmochem. Acta. 61:3399-3412.

Reiche, I., Berger, A., Görner, W., Merchel, S.,Radtke, M., Riederer, J., Riesemeier, H., and Roth, M., 2004. Following the traces of Albrecht Dürer: analysis of silverpoint drawings by spatially resolved synchrotron-induced X-ray fluorescence analysis. Nuclear Instruments and Methods in Physics Research Section B: Beam Interactions with Materials and Atoms., 226(1-2): 83-91.

Shaltoni, S., 1988. Geochemical Characteristics of the Mn Mineralization at Wadi Dana area/ South Jordan. M.Sc. Thesis. Univ. of Jordan. Amman. 130 pp.

Strub, E., Plarre, R., Radtke, M., Reinholz, U., Riesemeier, H., Schoknecht, U., Urban, K., Jungel, P., 2008. Determination of Cr (VI) in wood specimen: A XANES study at the CrK edge. Nuclear Instruments and Methods in Physics Research Section B-Beam Interactions with Materials and Atoms, 266(10):2405-2407. 